\title{
A EDUCAÇÃO AMBIENTAL COMO MEIO PARA A SUSTENTABILIDADE
}

Francisco Adjedam Gomes Oliveira ${ }^{1}$

Resumo: Este trabalho tem como objetivo estudar as contribuições da Educação Ambiental para a Sustentabilidade, assim como, a socialização destes conhecimentos. Para atingir tal objetivo será utilizada como metodologia de pesquisa uma abordagem bibliográfica. Concluiu-se que para um ambiente se tornar sustentável é necessário despertar nos cidadãos uma visão crítica, torná-los mais ativos e participativos na busca por políticas públicas ambientais, que a escola tem papel fundamental na formação destes cidadãos e que políticas públicas ambientais existem. Assim, a Educação Ambiental tem relação direta com a sustentabilidade, e com práticas educativas pode-se chegar a um ambiente sustentável.

Palavras-chave: Consumo; Globalização; Práticas Sustentáveis.

\footnotetext{
1 Especialista em Gestão Pública Municipal pela Universidade Estadual do Ceará (UECE), graduado em Ciências Econômicas pela Universidade Regional do Cariri (URCA), licenciando em Ciências Naturais e Matemática pela Universidade Federal do Ceará (UFCA). E-mail: fcoadjedam@hotmail.com
} 


\section{Introdução}

Problemas relacionados ao meio ambiente, gerados pela intervenção constante do homem, surgem a todo instante. A população mundial, que de acordo com Worldometers (2015) está acima de 7,3 bilhões de pessoas, com seu modo de vida consumista gera uma alta degradação ambiental.

O problema é que há uma relação estreita e forte entre o consumismo e o meio ambiente. Isso porque para atender a demanda da produção e do consumo é necessário retirar matérias primas da natureza, fabricar e transportar materiais, fazer grande uso de energia elétrica e de água, entre outros, tudo isso, gera emissão de gases poluentes, degradação e devastação ambiental, poluição geral e, consequentemente, a destruição de ecossistemas. Por este motivo várias instituições estão cada vez mais empregando o termo sustentabilidade na designação de suas ações (PENSAMENTO VERDE, 2014, on-line).

Pesquisadores de diversas áreas desenvolvem teorias que tentam explicar e prever situações que vinculam as questões ambientais e econômicas. Situações essas, que com o uso intenso dos recursos naturais tem proporcionado o aparecimento de fenômenos como: o aquecimento do planeta, doenças, desequilíbrio no regime de chuvas, desequilíbrio no regime de chuvas, aumento de furacões, tornados, alagamentos, secas, etc. Portanto, a humanidade busca, através de mecanismos de intervenção, tanto econômicos como de ordem legal, reduzir o ritmo, e em certos casos até reverter, às ações que prejudiquem o equilíbrio ambiental (DE LIMA, 2014, p.2).

Sobre o uso do termo sustentabilidade e seu vínculo com as necessidades sociais, o Centro de Estudos em Sustentabilidade da Fundação Getúlio Vargas (FGV - CES, 2008, p.1) afirma que:

Esta necessidade deriva da percepção de que a sociedade não mais aceita que externalidades negativas sejam lançadas sobre ela impunemente. Este cenário mais complexo aponta para inevitabilidade da integração de princípios de sustentabilidade na espinha dorsal das estratégias de negócio das companhias (FGV - CES, 2008, p.1).

De maneira geral o desenvolvimento sustentável é aquele que atende às necessidades do presente sem comprometer a possibilidade de as gerações futuras atenderem a suas próprias necessidades. A partir da definição de desenvolvimento sustentável pelo Relatório Brundtland, de 1987, pode-se perceber que tal conceito não diz respeito apenas ao impacto da atividade econômica no meio ambiente, se refere principalmente às consequências dessa relação na qualidade de vida e no bem-estar da sociedade, tanto presente quanto futura. Atividade econômica, meio ambiente e bem-estar da 
sociedade formam o tripé básico no qual se apoia a ideia de desenvolvimento sustentável.

Pressupõe-se então que o conhecimento e prática da Educação Ambiental de maneira eficiente servem para a melhoria não só na qualidade de vida e no bem-estar da sociedade, mais também para contribuir para um ambiente sustentável.

Desta forma, o presente trabalho tem os objetivos de estudar as contribuições da Educação Ambiental para Sustentabilidade por meio de uma abordagem bibliográfica, assim como, socializar estes conhecimentos com a comunidade científica, contribuindo para a Educação Ambiental em sociedade.

Esse trabalho está dividido em 5 (cinco) seções. A primeira seção trata da parte introdutória do trabalho, onde é evidenciada a contextualização e objetivos a serem atingidos. Na segunda seção é iniciado o referencial teórico, abordando a sustentabilidade de maneira ampla desde a sua origem que se deu com o questionamento sobre o crescimento populacional, passando pela sua evolução ao longo do tempo e finalizando com um aprofundamento sobre as práticas sustentáveis mais utilizadas atualmente.

A terceira seção discorre por literaturas conceituadas sobre a Educação Ambiental e as relações que esta mantém com sustentabilidade, pois sabe-se que em uma sociedade consumista é inevitável e indispensável à associação com a educação voltada para a preservação do meio ambiente.

Na seção seguinte, abordam-se as principais políticas públicas voltadas a Educação Ambiental existentes no Brasil, fazendo uma análise por estado das principais prioridades de acordo com as Secretarias Estaduais de Educação.

$\mathrm{Na}$ quinta seção são apresentadas as considerações finais, sintetizando - levantamento realizado. Aqui fica evidenciado que a pesquisa possui limitações às quais se caracterizam pela abordagem apenas bibliográfica, ou seja, que não possibilita experimentação ou quantificação de dados. No entanto, espera-se que como houve a difusão de várias definições e características de sustentabilidade e Educação Ambiental, seja possível a utilização deste para trabalhos futuros.

\section{Sustentabilidade: conceitos e ações}

Conforme Dalf (2010), a sustentabilidade é um termo usado para definir ações e atividades humanas que visam suprir às necessidades atuais sem comprometer o futuro das próximas gerações. Sendo assim, a sustentabilidade está diretamente relacionada ao desenvolvimento econômico e material sem agredir o meio ambiente, usando os recursos naturais de forma inteligente para que eles se mantenham no futuro. Seguindo estes parâmetros, a humanidade pode garantir o desenvolvimento sustentável. 
Ao longo do tempo o termo sustentabilidade sofreu um grande desgaste, pois se tornou a própria expressão do "absurdo lógico": desenvolvimento e sustentabilidade seriam logicamente incompatíveis (ALTVATER, 1995, p.305).

Podemos explicar tal incompatibilidade se levarmos em consideração o conceito de sustentabilidade e a explicação de Vasconcelos e Garcia (1998) sobre o que é desenvolvimento:

O desenvolvimento, em qualquer concepção, deve resultar do crescimento econômico acompanhado de melhoria na qualidade de vida, ou seja, deve incluir "as alterações da composição do produto e a alocação de recursos pelos diferentes setores da economia, de forma a melhorar os indicadores de bem-estar econômico e social (pobreza, desemprego, desigualdade, condições de saúde, alimentação, educação e moradia) (VASCONCELLOS; GARCIA, 1998, p. 205).

Dessa forma, se desenvolvimento é melhoramento das condições sociais, para Altvater (1995) é ilógico que se possa conseguir este desenvolvimento e ser sustentável. E ele tem uma parcela de razão, para que haja mais riqueza, emprego, igualdade social, mais saúde, alimentos e moradia, é necessário construir mais indústrias, hospitais, escolas e residências e, aí entra a questão: como fazer isto de maneira sustentável?

Segundo Benfica (2012) o conceito de desenvolvimento sustentável foi utilizado pela primeira vez na Assembléia Geral das Nações Unidas em 1979, indicando que o desenvolvimento poderia ser um processo integral que inclui dimensões culturais, éticas, políticas, sociais, ambientais, e não só econômicas. Esse conceito foi disseminado mundialmente pelos relatórios do Worldwatch Institute na década de 1980 e particularmente pelo relatório "Nosso Futuro Comum", produzido pela Comissão das Nações Unidas para o Meio Ambiente e Desenvolvimento em 1987.

Se considerarmos a sustentabilidade na perspectiva de muitos autores, onde sustentabilidade é mais do que um qualificativo do desenvolvimento, sendo uma perspectiva que vai além da preservação dos recursos naturais e da viabilidade de um desenvolvimento sem agressão ao meio ambiente, implicando em integração harmônica consigo mesmo, com o outro e com o ambiente, podemos fecundar a compreensão da educação com 0 novo conceito de sustentabilidade (BENFICA, 2012)

Segue então, a cronologia sintética de Gadotti que nos dá uma ideia histórica da relação sustentabilidade e educação:

A Unesco patrocinou em 1997 na Tessalônica (Grécia) uma conferência internacional sobre 'meio ambiente e sociedade', centrada no tema da educação. A Conferência da Tessalônica 
seguiu os passos das reuniões anteriores da Unesco - Tbilisi (1977), Jomtien (1990), Toronto (1992), Istambul (1993) - e a série de conferências das Nações Unidas iniciada em 1992 com a Rio-92, seguida pelas de 1994 no Cairo (população), em 1995em Copenhague (desenvolvimento social) e Beijing (sobre a mulher) e de1996 em Istambul (assentamentos humanos). Três anos antes, a Unesco havia lançado a iniciativa internacional sobre 'educação para um futuro sustentável', reconhecendo que a educação era a 'chave' do desenvolvimento sustentável e autônomo (GADOTTI, 2000, p. 87).

Aitvater (1995, p. 282) considera a teoria do "desenvolvimento sustentável do Relatório Brundtland - um desenvolvimento que satisfaz as necessidades do presente sem colocar em risco a possibilidade de satisfação das necessidades das gerações futuras - uma fórmula vazia”. Segundo ele, o sonho de um capitalismo ecológico é insustentável.

O conceito de "desenvolvimento" não é um conceito neutro, ele tem um contexto bem preciso dentro de uma ideologia do progresso, que supõe uma concepção de história, de economia, de sociedade e do próprio ser humano. $\mathrm{O}$ conceito foi utilizado numa visão colonizadora, durante muitos anos, no qual os países do globo foram divididos entre "desenvolvidos", "em desenvolvimento" e "subdesenvolvidos", remetendo-se sempre a um padrão de industrialização e de consumo. Existindo uma incompatibilidade de princípios entre sustentabilidade e capitalismo.

Quanto às práticas ou ações sustentáveis, existem dois instrumentos importantes para a implementação de "ações sustentáveis" são eles a Agenda $21^{2}$ e a Carta da Terra ${ }^{3}$. Eles foram gerados na ECO 92 e a Agenda 21 foi subscrita por 179 países. A expressão "Agenda" tem o sentido de planejar a participação de toda a sociedade civil, setor privado e governo, convocando-os para participar e assumir compromissos que visem solucionar problemas a curto, médio e longo prazo. A Agenda 21 prevê a implantação de uma Agenda 21 Nacional (em andamento), estadual e municipal, além disso, podendo ser aplicada em escolas, empresas, bairros e comunidades sendo um ótimo instrumento para o enraizamento de práticas sustentáveis onde vivemos, estudamos e trabalhamos (ENLAZADOR, 2007).

Enlazador (2007), em seu trabalho Almanaque para práticas sustentáveis, escrito com a participação e colaboração de muitas organizações, autores anônimos, donas de casa e sugestões de órgãos ambientais do poder público, enumera várias ações, que se aplicadas, contribuem para uma vida mais sustentável. As práticas sustentáveis começam no cotidiano, são dicas de

\footnotetext{
2 instrumento de planejamento para a construção de sociedades sustentáveis, em diferentes bases geográficas, que concilia métodos de proteção ambiental, justiça social e eficiência econômica.

${ }^{3}$ uma declaração de princípios éticos fundamentais para a construção de uma sociedade global justa, sustentável e pacífica.
} 
manejo sustentável de lâmpadas, papéis, reciclagem do lixo, aparelhos elétricos e produtos descartáveis. Depois, são dadas sugestões de receitas caseiras, econômicas e sustentáveis para a saúde humana, visando a substituição de produtos de limpeza que na maioria não são biodegradáveis e contaminam o solo, água e ar. Para adequar e racionalizar o consumo de combustível e consequentemente emitir menos gases poluentes, cuidados que se deve ter com os alimentos, faz um alerta e demonstra alternativas para um consumo racional de produtos destinados aos bebês, uso consciente da água e políticas públicas para minimizar a poluição das águas, entre outras.

Existem ainda práticas de incentivo ao desenvolvimento de produtos voltados à sustentabilidade que alguns institutos realizam. É o caso das práticas sustentáveis incentivadas por meio de concursos patrocinados pela Confederação Nacional da Indústria - CNI (Prêmio Gestão do Design Ecológico: iniciativas que estimulem processos ambientalmente sustentáveis) e da Federação das Indústrias do Estado de São Paulo - FIESP (Prêmio Ecodesign - estimula o uso de princípios ecológicos e tecnologias limpas no design de produtos, de embalagens e gráfico, como uma forma de competividade (FIESP, 2003; CNI, 2003).

No entanto, Chaves (2002) diz que na sua maioria, os designers brasileiros, desenvolvem seus projetos dentro do paradigma do custo (apenas econômico e não ambiental), da estética e das tendências do mercado. Conforme demonstrou a pesquisa feita com 12 dos designers mais atuantes no mercado moveleiro do Estado do Paraná e Santa Catarina. Na sua maioria, estes não compreendem o termo sustentabilidade, apresentando definições pouco aprofundadas e confusas, sem a noção que este conceito ultrapassa pressupostos já definidos no saber fazer ecodesign. A pesquisa também demonstra que mesmo que o conceito estivesse incorporado, estes profissionais declaram-se limitados para tomarem decisões diante das regras do mercado que impõem posturas como a de seguir tendências e reduzir os custos de produção.

\section{A Educação Ambiental como precursora da sustentabilidade}

A partir da Primeira Conferência das Nações Unidas sobre Meio Ambiente e Desenvolvimento, em Estocolmo em 1972, verificou-se que o planeta vive uma emergência socioambiental, que aponta para a necessidade de compatibilizar as atividades humanas e o crescimento econômico com a manutenção ecossistêmica (VEIGA, 2007). Surgem assim, inúmeras reflexões que colocam em tela as formas de relações sociais, meio ambiente e produção.

Mesmo diante de tantas evidências da ação do homem e suas consequências sobre o meio ambiente, ainda é pequeno o número de ações para implementação de políticas públicas, projetos e diretrizes que fomentem a consciência ambiental. Um grande avanço que precisa ser incorporado pelos estados e municípios foi a Lei que instituiu a Política Nacional de Educação Ambiental. Para o artigo 1ํ da Lei oㅜ 9.795/99 
entendem-se por educação ambiental os processos por meio dos quais o indivíduo e a coletividade constroem valores sociais, conhecimentos, habilidades, atitudes e competências voltadas para a conservação do meio ambiente, bem de uso comum do povo, essencial à sadia qualidade de vida e sua sustentabilidade (LEI 9.795, 1999, p.1).

A Educação Ambiental na escola constitui um caminho para promover mudanças necessárias nas práticas socioeconômicas, ilustrando, certos hábitos e visões individuais ou coletivos, independentemente das culturas, valores e hábitos existentes em diversos países (BRASIL, 2007; TRAJBER; MENDONÇA, 2006; UNESCO, 2003). Desta forma, uma importante estratégia constitui em trabalhar interdisciplinarmente novas propostas e políticas educacionais, de modo a formar cidadãos mais responsáveis e conscientes, na busca de soluções para as questões da degradação, preservação e sustentabilidade ambientais.

Sabe-se que "a educação sozinha não é suficiente para mudar os rumos do planeta, mas certamente é condição necessária para tanto" (PARÂMETROS CURRICULARES NACIONAIS, 2001, s/p).

Neste contexto, Pelicioni (1998, p.21) diz que "a escola, na medida em que possibilita a realização de um trabalho de intervenção sistemático, planejado e controlado, constitui um espaço privilegiado para 0 desenvolvimento da Educação Ambiental".

Cabe destacar que a Educação Ambiental assume cada vez mais uma função transformadora, na qual a co-responsabilização dos indivíduos torna-se um objetivo essencial para promover um novo tipo de desenvolvimento - 0 desenvolvimento sustentável (JACOBI, 2003).

Para tanto é preciso que se criem todas as condições para facilitar o processo, suprindo dados, desenvolvendo e disseminando indicadores e tornando transparentes os procedimentos por meio de práticas centradas na Educação Ambiental que garantam os meios de criar novos estilos de vida e promovam uma consciência ética que questione 0 atual modelo de desenvolvimento marcada pelo caráter predatório e pelo reforço das desigualdades socioambientais (JACOBI, 2003).

Segundo Reigota (1998), a Educação Ambiental aponta para propostas pedagógicas centradas na conscientização, mudança de comportamento, desenvolvimento de competências, capacidade de avaliação e participação dos educandos.

Para Sorrentino (1998), os grandes desafios para os educadores ambientais são, de um lado, o resgate e o desenvolvimento de valores e comportamentos (confiança, respeito mútuo, responsabilidade, compromisso, solidariedade e iniciativa) e de outro, o estímulo a uma visão global e crítica 
das questões ambientais e a promoção de um enfoque interdisciplinar que resgate e construa saberes.

Os temas predominantes nas atividades feitas em relação à Educação Ambiental são lixo, proteção do verde, uso e degradação dos mananciais, ações para conscientizar a população em relação à poluição do ar. A Educação Ambiental que tem sido desenvolvida no país é muito diversa, e a presença dos órgãos governamentais como articuladores, coordenadores e promotores de ações é ainda muito restrita (JACOBI, 2003).

A Educação Ambiental transformadora, articulada com a mudança social, transforma a pedagogia em uma prática política, como sugere Giroux (2003), com uma cooperação entre educadores/as e outros sujeitos culturais engajados nas lutas sociais e ambientais, criando espaços críticos de aprendizagem dentro e fora da escola, buscando a união com movimentos sociais organizados. Assim, Tristão (2007) diz que as mudanças não ocorrerão de cima para baixo, mas com a participação direta de alunos/as, professores/as, comunidade, meio ambiente, numa dinâmica complexa.

No âmbito de participação social, a Educação Ambiental na modernidade reflexiva também pode favorecer uma "vida democrática de alta intensidade" (SANTOS, 2003), promovendo espaços de (inter)locução e participação - como forma de ampliar a democracia - e de intervenção sóciopolítica, para enfrentamento coletivo da crise ambiental, como também com o intuito de prevenir, atenuar ou eliminar riscos.

Para Mota (2004) quando gestores públicos compreendem a importância desses espaços dialógicos e participativos, os princípios da legitimidade, eficiência e cidadania adquirem visibilidade na governança democrática.

De acordo com o Barbosa (2008), os princípios e o plano de ação propostos pelo Tratado de Educação Ambiental para Sociedades Sustentáveis e Responsabilidade Global apontam para esse novo paradigma e uma outra governança, pautada numa ética e estilos de vida que conduzam à construção de "sociedades sustentáveis", a partir de uma educação voltada para a cidadania ambiental e a responsabilidade global.

A utilização da expressão "sociedades sustentáveis", ao invés da difundida ideia de desenvolvimento sustentável, supõe uma alteração substantiva do modo de conceber as formas de produção e de consumo que geram desigualdades sociais e acentuam a pobreza. Essa elaboração fortalece a perspectiva e as práticas de uma Educação Ambiental popular, participativa, crítica, transformadora e emancipatória, como também vem influenciando largamente a elaboração de políticas públicas socioambientais no Brasil.

Assim, o meio ambiente é pensado como espaço relacional. E o ser humano, nele presente, é tido como agente que interage no interior de uma complexa teia de relações e significados. 


\section{Políticas públicas e ações para a sustentabilidade}

Quanto à participação do governo na implantação de uma política de Educação Ambiental nos espaços educacionais, verifica-se que a Política Nacional de Educação Ambiental (PNEA) - instituída pela Lei no 9.795/99 - e seu decreto de regulamentação em 2002 têm contribuído para acelerar o processo de institucionalização da Educação Ambiental no país, cujo marco inicial, pelo menos para o ensino formal, foi a Lei no 6.938/81, a qual, ao instituir a Política Nacional de Meio Ambiente, determinou a inclusão da Educação Ambiental em todos os níveis de ensino 4 .

O Programa Nacional de Educação Ambiental (ProNEA), que tem a missão de contribuir com a educação para a sustentabilidade e uma sociedade educada ambientalmente, após a regulamentação da PNEA em 2002, vem fortalecendo o Sistema Nacional de Meio Ambiente com a implementação desta política em regime de colaboração com os entes da Federação.

O MEC, por meio da Coordenação-Geral de Educação Ambiental (CGEA), e o Ministério do Meio Ambiente, por meio do Departamento de Educação Ambiental (DEA), coordenam a PNEA e o ProNEA. Mas, em razão da transversalidade da Educação Ambiental, outras instituições públicas federais (ministérios, autarquias, estatais etc.) vêm desenvolvendo ações neste campo (BARBOSA, 2008).

O governo sabe que quanto mais pessoas envolvidas e engajadas no enraizamento de Educação Ambiental as chances de sucesso serão bem maiores. E no sentido de gestão compartilhada entre os sistemas de ensino e de meio ambiente, criou-se os chamados Coletivos Educadores que têm o papel de articular as instituições que já atuam com processos formativos no município, com o intuito de desenvolver um processo continuado de formação de educadores ambientais e auxiliar na implementação de políticas públicas e as Comissões de Meio Ambiente e Qualidade de Vida (Com-Vidas) que por sua vez, estimulam o diálogo escola/comunidade com foco na Educação Ambiental, articulando saberes e ações que a modernidade, com suas instituições disciplinares, fragmentou e dissociou.

Há um entendimento de que as políticas públicas de Educação Ambiental devem induzir à produção de ações transformadoras que contribuam na prevenção e enfrentamento dos riscos globais, apoiadas numa governança democrática mais intensa, que estimule a reflexividade e a cidadania ambiental (BARBOSA, 2008).

\footnotetext{
4 A criação da Secretaria Especial do Meio Ambiente (SEMA), em 1973, ligada à Presidência da República representou o começo da institucionalização da EA no âmbito do governo federal. A EA é proposta como política pública a partir da Conferência de Estocolmo, realizada em 1972. A partir de então houve pressões internacionais para a introdução de políticas públicas ambientais na agenda de governo dos países.
}

revista brasileira educação ambiental 
Percebe-se que são muitos os esforços governamentais para instigar uma adesão da sociedade à questão ambiental através da educação. E neste cenário, Barbosa (2008) em sua pesquisa sobre Políticas Públicas de Educação Ambiental com as Secretarias de Educação dos Estados Brasileiros, apresenta os principais desafios das SEDUCs no que se refere às políticas estaduais de Educação Ambiental e agrupa de modo hierárquico, as prioridades informadas por gestores e técnicos responsáveis pela coordenação da Educação Ambiental nos Estados e no Distrito Federal. As prioridades apresentadas se encontram na Tabela 1.

Tabela 1: Prioridades das políticas públicas de Educação Ambiental nos Estados.

\begin{tabular}{|c|c|c|}
\hline ORDEM & UFs & DESAFIOS \\
\hline 1 & $\begin{array}{l}\text { AC, AL, AP, } \\
\text { BA, CE, DF, ES, GO, MA, MS, } \\
\text { MT, PA, PB, PE, PI, PR, RJ, RN, } \\
\text { RO, RR, SC, SP e TO }\end{array}$ & $\begin{array}{l}\text { Formação continuada dos professores em } \\
\text { educação ambiental. }\end{array}$ \\
\hline 2 & $\begin{array}{l}\text { AC, AM, AP, CE, DF, ES, } \\
\text { MG, MS, PB, PI, PR, RN, RO, } \\
\text { RR, RS, SC e SE }\end{array}$ & $\begin{array}{l}\text { Inserção curricular qualificada, } \\
\text { estimulando a abordagem da EA no } \\
\text { projeto político-pedagógico das escolas. }\end{array}$ \\
\hline 3 & $\begin{array}{l}\text { AL, MA, MS, PA, PB, PE, PI, RN, } \\
\text { RO e TO }\end{array}$ & $\begin{array}{l}\text { Incentivo à criação e fortalecimento de } \\
\text { Com-Vidas. }\end{array}$ \\
\hline 4 & BA, ES, MG, PA, SC, SE, SP e TO & Institucionalização da EA na SEDUC. \\
\hline 5 & $A L, B A, C E, D F, P E$ e RS & $\begin{array}{l}\text { Monitoramento e avaliação das ações e } \\
\text { projetos de EA. }\end{array}$ \\
\hline \multirow{3}{*}{6} & GO, MT e RJ & $\begin{array}{l}\text { Apoio ao controle social da EA - redes, } \\
\text { colegiados, fóruns, comitês, Coletivos }\end{array}$ \\
\hline & RJ, RR e SE & Política de financiamento para EA. \\
\hline & $A M, G O$ e $R S$ & $\begin{array}{l}\text { Universalização da EA em toda a educação } \\
\text { básica. }\end{array}$ \\
\hline \multirow[t]{2}{*}{7} & AP e SP & $\begin{array}{l}\text { Formação inicial e continuada das } \\
\text { equipes gestoras e técnicas em EA. }\end{array}$ \\
\hline & AM e MT & Gestão compartilhada e participative. \\
\hline 8 & MA & $\begin{array}{l}\text { Participação das regionais de ensino nos } \\
\text { Coletivos. }\end{array}$ \\
\hline
\end{tabular}

Fonte: Barbosa (2008, p. 16)

Destacam-se nesta pesquisa, a formação continuada dos professores em Educação Ambiental que é prioritária para 23 estados, ou seja, $85 \%$ das Unidades Federativas, a inserção curricular qualificada, prioridade para 17 ou (63\%) dos estados e fortalecimento de Com-Vidas, com 10 estados ou (37\%) das indicações entre as três principais prioridades identificadas.

Barbosa (2008, p.17) faz ainda uma análise dos desafios da Educação Ambiental nos sistemas estaduais de ensino de acordo com a sequência prioritária de cada UF, de modo a especificar as três maiores prioridades identificadas pelas SEDUCs relacionadas às atividades e projetos no ensino. É o que se pode observar na Tabela 2 abaixo: 
Tabela 2: Desafio da Educação Ambiental nos sistemas estaduais de ensino.

\begin{tabular}{|c|c|c|}
\hline Desafios & UFs & Ordem Prioritária \\
\hline \multirow{3}{*}{$\begin{array}{l}\text { Formação continuada dos } \\
\text { professores em educação ambiental. }\end{array}$} & $\begin{array}{l}\text { AL, DF, GO, MA, MS, MT, PB, PE, } \\
\text { PR, RJ, RR, SC }\end{array}$ & Prioridade $\mathrm{n}^{\circ} 1$ \\
\hline & $\mathrm{AC}, \mathrm{AP}, \mathrm{CE}, \mathrm{ES}, \mathrm{PA}, \mathrm{PI}, \mathrm{RN}, \mathrm{RO}$, & Prioridade $\mathrm{n}^{\circ} 2$ \\
\hline & $\mathrm{BA}, \mathrm{SP}$ & Prioridade $\mathrm{n}^{\circ} 3$ \\
\hline \multirow{3}{*}{$\begin{array}{l}\text { Inserção curricular qualificada, esti- } \\
\text { mulando abordagem da EA no pro- } \\
\text { jeto político-pedagógico das escolas. }\end{array}$} & $\mathrm{AC}, \mathrm{CE}, \mathrm{PI}, \mathrm{RN}$ & Prioridade $\mathrm{n}^{0} \mathrm{1}$ \\
\hline & AM, DF, PB, PR, RR, RS, SC, SE & Prioridade $\mathrm{n}^{\circ} 2$ \\
\hline & $\mathrm{AP}, \mathrm{ES}, \mathrm{MG}, \mathrm{MS}, \mathrm{RO}$ & Prioridade $\mathrm{n}^{\circ} 3$ \\
\hline \multirow{3}{*}{$\begin{array}{l}\text { Incentivo à criação e fortalecimento } \\
\text { de Com-Vidas. }\end{array}$} & $\mathrm{RO}$ & Prioridade $\mathrm{n}^{\circ} \mathrm{1}$ \\
\hline & $\mathrm{AL}, \mathrm{MA}, \mathrm{MS}, \mathrm{PE}$ & Prioridade $\mathrm{n} \div 2$ \\
\hline & PA, PB, PI, RN, TO & Prioridade $\mathrm{n}^{\circ} 3$ \\
\hline \multirow{3}{*}{$\begin{array}{l}\text { Institucionalização da EA na } \\
\text { SEDUC. }\end{array}$} & BA, ES, MG, PA, SE, SP, TO & Prioridade $\mathrm{n}^{\circ} 1$ \\
\hline & - & Prioridade $\mathrm{n}^{\circ} 2$ \\
\hline & SC & Prioridade $\mathrm{n}^{\circ} 3$ \\
\hline \multirow{3}{*}{$\begin{array}{l}\text { Monitoramento e avaliação das } \\
\text { ações e projetos de EA. }\end{array}$} & - & Prioridade $\mathrm{n}^{0} 1$ \\
\hline & BA & Prioridade nำ 2 \\
\hline & $\mathrm{AL}, \mathrm{CE}, \mathrm{DF}, \mathrm{PE}, \mathrm{RS}$ & Prioridade $\mathrm{n}^{\circ} 3$ \\
\hline \multirow{3}{*}{$\begin{array}{l}\text { Apoio ao controle social da EA - } \\
\text { redes, colegiados, fóruns, comitês, } \\
\text { Coletivos. }\end{array}$} & - & Prioridade $\mathrm{n}^{0} 1$ \\
\hline & $\mathrm{GO}, \mathrm{RJ}$ & Prioridade $\mathrm{n}^{0} 2$ \\
\hline & MT & Prioridade $n^{\circ} 3$ \\
\hline \multirow{3}{*}{ Política de financiamento para EA. } & - & Prioridade $\mathrm{n}^{0} 1$ \\
\hline & - & Prioridade $\mathrm{n}^{\circ} 2$ \\
\hline & RR, SE, RJ & Prioridade $\mathrm{n}^{\circ} 3$ \\
\hline \multirow{2}{*}{$\begin{array}{l}\text { Universalização da EA em } \\
\text { toda a educação básica. }\end{array}$} & $\mathrm{RS}$ & Prioridade $\mathrm{n}^{0} 1$ \\
\hline & - & Prioridade $\mathrm{n}^{\circ} 2$ \\
\hline \multirow{3}{*}{$\begin{array}{l}\text { Formação inicial e continuada das } \\
\text { equipes gestoras e técnicas em EA. }\end{array}$} & AM, GO & Prioridade $\mathrm{n}^{0} 3$ \\
\hline & $\mathrm{AP}$ & Prioridade $\mathrm{n}^{0} 1$ \\
\hline & ST & $\begin{array}{l}\text { Prioridade } n^{-2} \\
\text { Prioridade } n^{\circ} 3\end{array}$ \\
\hline \multirow[t]{3}{*}{ Gestão compartilhada e participative. } & AM & Prioridade $\mathrm{n}^{\circ} \mathrm{1}$ \\
\hline & MT & Prioridade $\mathrm{n}^{\circ} 2$ \\
\hline & - & Prioridade $\mathrm{n}^{\circ} 3$ \\
\hline \multirow{3}{*}{$\begin{array}{l}\text { Participação das regionais de } \\
\text { ensino nos Coletivos Educadores. }\end{array}$} & - & Prioridade $\mathrm{n}^{0} 1$ \\
\hline & - & Prioridade $\mathrm{n}^{\circ} 2$ \\
\hline & $\mathrm{MA}$ & Prioridade $\mathrm{n}^{0} 3$ \\
\hline \multirow{3}{*}{$\begin{array}{l}\text { Outros: MG - projetos especiais (Ma- } \\
\text { nuelzão/UFMG; "Caminho das } \\
\text { Águas"; e outros); AC - Apoio ao } \\
\text { trabalho do Coletivo Jovem junto à } \\
\text { formação das Com-Vidas; PR - } \\
\text { Produção de material pedagógico } \\
\text { sobre EA. }\end{array}$} & - & Prioridade $n^{\circ} 1$ \\
\hline & MG & Prioridade $n^{\circ} 2$ \\
\hline & $A C, P R$ & Prioridade $n^{\circ} 3$ \\
\hline
\end{tabular}

Fonte: Barbosa (2008, p. 17)

Identificando por exemplo as prioridades para o Estado do Ceará percebe-se que em ordem de importância são:

1. Inserção curricular qualificada, estimulando a abordagem da EA no projeto político-pedagógico das escolas;

2. Formação continuada dos professores de Educação Ambiental;

3. Monitoramento e avaliação das ações e projetos de EA. 
Verificando as prioridades para o Estado de São Paulo temos:

1. Institucionalização da Educação Ambiental na Secretaria de Educação;

2. Formação inicial e continuada das equipes gestoras e técnicas em Educação Ambiental;

3. Formação continuada dos professores em Educação Ambiental.

O mesmo pode ser feito para cada Estado.

\section{Conclusões}

É necessário colocar o direito a um ambiente saudável no mesmo nível de direito ao acesso a renda, saúde, habitação, educação e lazer.

A globalização estimula o superconsumo e gera pressões sobre os recursos naturais sem contabilizar os custos sociais e ambientais da produção.

Maiores incentivos a pesquisas científicas podem transformar elementos da biodiversidade em produtos de mercado, em áreas como medicamentos, alimentos, cosméticos, fertilizantes, pesticidas e solventes naturais.

A parceria entre sociedade civil, poder público e setores privados é a tônica principal para o enriquecimento e materialização dos debates. Todos podem e devem se envolver com a temática socioambiental. O meio ambiente ecologicamente equilibrado é um bem de uso comum do povo e fundamental para a sadia qualidade de vida. Assim é válido o artigo 225 da Constituição Federal, citando o poder público e à coletividade o dever de defendê-lo e preservá-lo para as presentes e futuras gerações.

É sabido que a Educação Ambiental, quando bem aplicada, leva a muitas e perceptíveis mudanças no comportamento pessoal, atividades e valores de cidadania que trazem mudanças de ordem sociais. Isso se concretiza pela adoção de uma abordagem metodológica interdisciplinar, da complexidade do conhecimento baseado em valores e práticas sustentáveis, indispensáveis para estimular o interesse e o engajamento de cidadãos na ação e na responsabilização. A Educação Ambiental deve ser vista como um processo de permanente aprendizagem que valoriza as diversas formas de conhecimento e forma cidadãos com consciência local e planetária.

O papel dos professores(as) é essencial para impulsionar as transformações de uma educação que assume um compromisso com a formação de valores de sustentabilidade. A Educação Ambiental é essencial para despertar nas pessoas a responsabilidade que cada um deve ter na construção de uma sociedade mais equitativa e ambientalmente sustentável.

As políticas públicas de Educação Ambiental existem e são muitas as pessoas e entidades envolvidas. Os principais desafios destas políticas públicas de Educação Ambiental no Brasil identificados pelos gestores estaduais e os compromissos assumidos pelo Órgão Gestor da Política 
Nacional de Educação Ambiental, em regime de colaboração com os entes federados, apontam para uma proposta político-pedagógica de educação para a sustentabilidade capaz de formar pessoas e coletividades responsáveis pela melhoria da qualidade de vida e do ambiente em que vivem.

Todo o esforço realizado para atingir os objetivos acerca dos desafios e compromissos têm produzido políticas públicas que estimulam a participação cidadã, a solidariedade no sentido da prevenção e enfrentamento dos riscos globais do mundo contemporâneo e a valorização da diversidade biológica e cultural.

\section{Referências}

ALTVATER, E. O preço da Riqueza: pilhagem ambiental e a nova (des)ordem mundial. São Paulo: UNESP, 1995.

BARBOSA, L.C. Políticas públicas de educação ambiental numa sociedade de risco: tendências e desafios no Brasil. Anais do IV Encontro Nacional da Anppas, v. 4, n. 5, p. 1-21, 2008.

BENFICA, G. Sustentabilidade e educação. Seara - Revista Virtual de Letras e Cultura, 2012.

BRASIL, Ministério da Educação (MEC), Secretaria de Educação Continuada, Alfabetização e Diversidade (Secad/MEC). Educação Ambiental: aprendizes de sustentabilidade. Brasília: MEC/Secad, 2007.

Chaves, L.I. Parâmetros ambientais no planejamento de móveis seriados de madeira de acordo com relatos de designers. Dissertação de mestrado defendida no Programa de Pós-graduação em Tecnologia - PPGTE, Centro Federal de Educação Tecnológica do Paraná, Curitiba. P 138, 2002.

CNI - Prêmio Design. Confederação Nacional da Indústria - CNI, 2003. Disponível em: <http://www.cni.org.br> Acesso em: 29 mai. 2015.

DALF, R. Administração: a ética da sustentabilidade e o meio ambiente, São Paulo: Cengage Learning, 2010.

ENLAZADOR, T.Almanaque para práticas sustentáveis. Recife: Unimed, 2007.

FIESP. Produtos Ecoeficientes. Federação das Indústrias do Estado de São Paulo - FIESP, 2003. Disponível em: <http://www.fiesp.com.br> Acesso em: 29 mai. 2015.

GADOTTI, M. Pedagogia da Terra. São Paulo: Peirópolis, 2000.

GIROUX, H. A prática política dos estudos culturais. Porto Alegre: ARTMED, 2003.

JACOBI, P. et al. Educação ambiental, cidadania e sustentabilidade. Cadernos de pesquisa, v. 118, n. 3, p. 189-205, 2003. 
BRASIL. Casa Civil. Lei No. 9.795, de 27 de Abril de 1999. Dispõe sobre a educação ambiental, institui a Política Nacional de Educação Ambiental e dá outras providências. Brasília, 1999. Disponível em:

<http://www.planalto.gov.br/ccivil 03/leis/l9795.htm> Acesso em: 29 mai. 2015.

MOTA, C.R. As novas formas de participação social nas políticas públicas: os conselhos gestores de políticas sociais. Revista Virtual de Gestão de Iniciativas Sociais, $\mathrm{n}^{\circ} \mathrm{0}$, out. 2004, p. 36-44

PARÂMETROS CURRICULARES NACIONAIS: meio ambiente: saúde/ Ministério da Educação. Secretaria da Educação Fundamental. $3^{\text {a }}$ ed. Brasília: A Secretaria, 2001.

PELICIONI, A.F.; RIBEIRO, H. Percepções e práticas de estudantes a respeito de meio ambiente, problemas ambientais e saúde. 1998, p. 1-8. Disponível

$<$ http://www.bvsde.paho.org/bvsaidis/eduamb/peru/braesp278.pdf>. Acesso em: 29 mai. 2015.

População mundial atual, 2015. Disponível em:

<http://www.worldometers.info/br/>. Acesso em: 30 abr. 2015.

PENSAMENTOVERDE. Como o consumo desenfreado prejudica o meio ambiente. Disponível em: <http://www.pensamentoverde.com.br/meioambiente/como-o-consumo-desenfreado-prejudica-o-meio-ambiente/> Acesso em: 30 abr. 2015.

REIGOTA, M. Desafios à educação ambiental escolar. In: JACOBI, P. et al. (orgs.). Educação, meio ambiente e cidadania: reflexões e experiências. São Paulo: SMA, 1998. p.43-50.

SANTOS, B.S. (org.). Democratizar a democracia: os caminhos da democracia participativa. $2^{\mathrm{a}}$ ed. Rio de Janeiro: Civilização Brasileira, 2003

SORRENTINO, M. De Tbilisi a Tessaloniki, a educação ambiental no Brasil. In: JACOBI, P. et al. (orgs.). Educação, meio ambiente e cidadania: reflexões e experiências. São Paulo: SMA.1998. p.27-32.

TRAJBER, Rachel; MENDONÇA, Patrícia Ramos. 0 que fazem as escolas que dizem que fazem Educação Ambiental? UNESCO, 2006.

TRISTÃO, M. A educação ambiental e os contextos formativos na transição de paradigmas. In: REUNIÃO ANUAL DA ANPEd, 30., 2007, Caxambu. Anais... Caxambu: ANPEd, 2007.

UNESCO. Cultura científica um direito de todos. Brasília:UNESCO, 2003. Disponível em: $<$ http://unesdoc.unesco.org/images/0013/001335/133538por.pdf>. Acesso em: 30 abr. 2015.

VEIGA, J.E. Desenvolvimento sustentável: o desafio do século XXI. Rio de Janeiro: Garamond, 2005. 